\title{
Evaluation of Training Program for Nursing Students on Testicular Cancer and Testicular Self-Examination
}

\author{
Selen Ozakar Akca1 ${ }^{1,}$ (iD) , Tugba Cengiz², Dilara Aydın³ ${ }^{3}$ Simge Diker $^{2}$ and Tuğba Özdemir ${ }^{2}$ \\ ${ }^{1}$ Associate Professor, Department of Child Health and Diseases Nursing, Faculty of Health Sciences, Hitit University, Corum, Turkey \\ 2 MSc, Department of Child Health and Diseases Nursing, Faculty of Health Sciences, Hitit University, Corum, Turkey \\ 3 MSc, Department of Child Health and Diseases Nursing, Faculty of Health Sciences, Amasya University, Amasya, Turkey
}

* Corresponding author: Selen Ozakar Akca, Department of Child Health and Diseases Nursing, Faculty of Health Sciences, Hitit University, Corum, Turkey. Tel: +903642230732; Email: selenozakar@hotmail.com

Received 2020 November 15; Revised 2020 December 02; Accepted 2020 December 18.

\begin{abstract}
Background: Testicular self-examination (TSE) is one of the most effective ways for the early detection of testicular cancer. The Medical Association and American Urological Association recommend raising the awareness of TSE and educating the public in this regard for early diagnosis.

Objectives: The present study aimed to evaluate the effect of the training given to nursing students for testicular cancer and TSE on the knowledge levels of the students.

Methods: The current single-group pretest-posttest quasi-experimental study was carried out on the students continuing their education and training in the Faculty of Health Sciences of a university in Turkey within 2018 and 2019 (n=83). No sample selection was made for the determination of the study subjects $(n=56)$. The research data were collected using a questionnaire. The data were evaluated by appropriate statistical methods, and a p-value of less than 0.05 was considered statistically significant.

Results: The students participating in the study were within the age range of 20-26 years. In addition, $51.8 \%$ of the study subjects were male. Moreover, $58.9 \%$ of the students in the study stated that they did not receive any training for testicular cancer and TSE. Furthermore, $80.4 \%$ of the male students did not perform TSE $43.6 \%$ of whom reported that they did not know how to do it. However, the mean test scores of the participants for testicular cancer and TSE were reported as 12.84 and 15.73 prior to and after the training, respectively, with a statistically significant difference $(\mathrm{P}<0.01)$. Nevertheless, the rate of TSE among the students was previously reported as $19.6 \%$ and increased to $100 \%$ after the training.

Conclusion: In this study, it was concluded that the participants, even with an ordinary awareness-raising campaign, could be informed about testicular cancer and TSE. It is recommended to raise the awareness of society in this regard through well-planned educational
\end{abstract} activities.

Keywords: Disease prevention, Testicular cancer, Testicular self-examination, Testis

\section{Background}

As one of the most important health problems with a rising prevalence, testicular cancer is ranked second after leukemia as a malignancy among males within the age range of 20-35 years (1). The incidence of testicular cancer differs according to countries, races, and socioeconomic classes and appears to be about twice lower in individuals with a higher socioeconomic level in comparison to that reported for those with a lower socioeconomic level $(2,3)$. It is stated that there were 5.9 new cases of testicular cancer in 100,000 men every year within 2012 and 2016, and $0.3 \%$ of these cases resulted in mortality. In the United States, the number of male patients with testicular cancer was 263,137 in 2016 (4). In Turkey, testicular cancer is the most common cancer among men within the age range of 15-24 years with a rate of $24.8 \%$ (5).

Although it is known that some congenital and acquired factors are related to the development of testicular tumors, the cause of testicular cancer is not fully known. It is reported that the strongest known relationship is with an undescended testicle (cryptorchidism), and those with a history of cryptorchidism are four to six times more likely to have testicular cancer. In addition, $5-10 \%$ of testicular tumors occur in the normal descended testicle (6). Patients generally consult a physician for unilateral painless swelling and mass in the scrotum. About $10 \%$ of patients are asymptomatic and often noticed post-traumatically or by the patient's sexual partner. Although testicular cancer is a type of cancer spreading quite rapidly, the prognosis of the disease is good when detected early, and the 5-year life span in stage I is reported as 99\% (7). Therefore, early diagnosis and treatment are substantially important in testicular cancer.

Ultrasound, transillumination, and computed tomography are among the main diagnostic methods of testicular cancer. It is very important for individuals to be aware of the importance of early diagnosis and perform testicular self-examination (TSE), which is one of the most effective ways for early detection (8). The TSE is a regular examination carried out by the individual himself at least once a 
month using both hands; while fixing the testicle with one hand, the other hand checks the testicles to find any mass during and after a shower against a mirror $(9,10)$. Once performed regularly every month, TSE helps the individual to recognize his testicular tissue, thereby providing the early recognition of any changes with the testicles. The TSE is easy to learn and apply, safe, economical, non-invasive, and time-saving and does not need any special equipment $(9,11)$.

A body of the literature determined that young men did not have sufficient knowledge of the prevalence of testicular cancer and reported that they almost never performed TSE $(6,12,13)$. The American Medical Association and American Urological Association also recommend informing and educating the public about TSE for early diagnosis, and this recommendation is evidenced by numerous studies demonstrating the importance of the clinical-stage in diagnosis (14-16). Therefore, it is necessary to raise the awareness of the public regarding testicular cancer and TSE.

This awareness-raising of TSE can be achieved through several ways, such as film screenings, written materials, and practical training $(17,18)$. In this process, considering that they play an active role in health assessment, education, counseling, referral, and screening services for early diagnosis, nurses have an important contribution to the protection and development of health in every period of the individuals' lives $(15,19)$.

\section{Objectives}

With this background in mind, the current study aimed to evaluate the effectiveness of a training program given to nursing students on testicular cancer and TSE.

\section{Methods}

\subsection{Type of study}

The present single-group pretest-posttest quasiexperimental study was carried out on the students of the Nursing Department in the Faculty of Health Sciences in a university in Turkey.

\subsection{Study population}

The population was composed of the junior nursing students continuing their education and training in the fall semester of 2018-2019 in the Faculty of Health Sciences of a university in the Anatolian region of Turkey $(n=83)$. No sample selection was made for the determination of the study subjects, and 56 junior nursing students from the faculty during the study period $(20 / 10 / 2018$ to $15 / 12 / 2018$ ) who met the study criteria and were willing to participate in the study voluntarily formed the sample of the study. The inclusion criteria of the present study were studying in the fall semester of the 2018-2019 academic year, being a junior student in the Nursing Department of Faculty of Health Sciences, not having a problem preventing communication, being a volunteer, and be willing to participate in the study. Those who were not junior students of the Nursing Department of Faculty of Health Sciences and those who do not agree to participate were excluded from the study. In addition, $67.5 \%$ of the whole population was able to be reached due to the fact that a certain number of students did not attend the classes at the time of the study.

\subsection{Data collection tools}

The research data were collected using a questionnaire form. This form, developed in line with previous studies $(8,15,17-19)$, consists of three sections. The first part of the questionnaire includes 9 items for the determination of the introductory features of the students. The second part has 7 items for the determination of the introductory features of students related to testicular cancer and TSE. Finally, the third part consists of a 20-item knowledge test for the determination of their knowledge levels of testicular cancer symptoms and TSE, with a total of 36 items. In the knowledge test for the determination of students' testicular cancer symptoms and knowledge levels of TSE, participants answering each question correctly were given a score of 1 , and those answering incorrectly were given a score of 0 . The level of knowledge of the participants was calculated by the sum of these points. A maximum of 20 and minimum of 0 points can be obtained from the test. The preliminary test of the questionnaire was conducted among 10 students, and the errors observed in application, understandability, and data entry were corrected. The students who pretested the form and were not present at the faculty during the course of the study were excluded. The research data were obtained from the questionnaire filled out before the training and 1 month after the training by a total of 56 students divided into two groups of 28 subjects (Figure 1).

The training program for students on testicular cancer and TSE covers the topics of the importance of testicles for the life of male individuals, definition of testicular cancer, its symptoms, early diagnostic methods, risk factors, protection from testicular cancer, and technique of performing TSE. The training was carried out in the form of presentation, discussion, demonstration, and question and answer. A testicle model, written material, and PowerPoint presentation were used during the training lasting for 40-50 min. During the training, 56 students were divided into two groups of 28 individuals, through which it was ensured that the study group was better controlled, their motivation was not impaired, and the training was carried out more effectively. The 


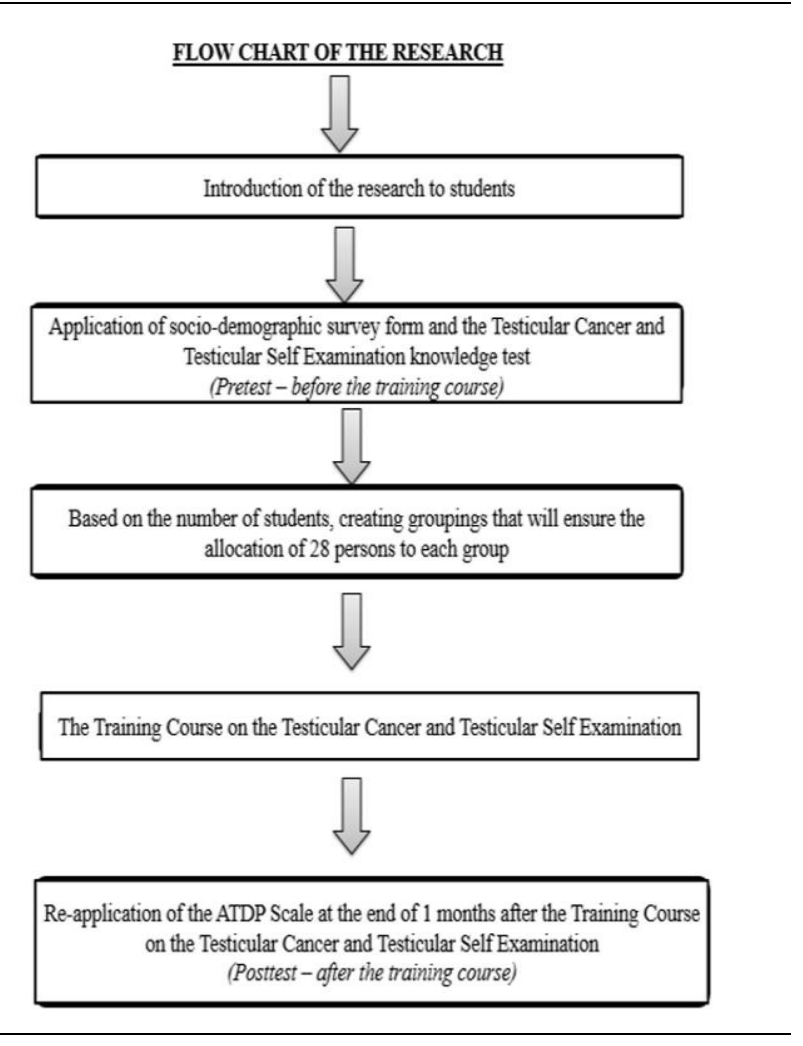

Figure 1. Flowchart of the research

same researchers gave the training with the same educational materials for a similar duration of time.

This study was conducted based on obtaining the approval of the Ethics Committee of the Faculty of Health Sciences and in accordance with the rules of the Helsinki Declaration. The approval of the Ethics Committee and written permission from the Faculty of Health Sciences were obtained for the study. The purpose of the study was explained by interviewing face-to-face with the students who participated in the study, and written volunteer approval was obtained using an informed consent form.

\subsection{Statistical analysis}

Statistical analysis was performed using SPSS software (version 22.0). Quantitative variables were presented as mean and standard deviation. Moreover, categorical variables were presented as numbers and percentages. The comparison of the knowledge test according to before and after the training score averages was performed using McNemar's test. Furthermore, one-way analysis of variance was used for the comparison of more than two groups in accordance with the data normality distribution in comparing the knowledge test mean scores according to the introductory characteristics of the students. The dependent sample t-test (paired sample t-test) was utilized for the comparison of the mean scores of students before and after the training. A p-value of less than 0.05 was considered statistically significant.

\section{Results}

The students participating in the study were within the age range of 20-26 years, $75.0 \%$ of whom were within the age range of 20-22 years. In the present study, $51.8 \%$ of the subjects were male. Table 1 tabulates certain introductory features of the students in the study. Table 2 shows that $94.6 \%$ of the students participating in the study heard about testicular cancer. Moreover, $75.0 \%$ of the subjects received information on testicular cancer, out of whom $30.9 \%$ obtained the information from the internet, $83.9 \%$ heard about TSE, and $58.9 \%$ reported no training for testicular cancer and TSE. In addition, $80.4 \%$ of the male students participating in the study stated that they did not perform TSE $43.6 \%$ of whom reported that they did not know how to do it.

The proportion of correct answers given by the students participating in the study to the 20 -item test of knowledge related to testicular cancer and TSE increased after the training, compared to that reported before the training (Table 3 ). The mean scores of the knowledge test were 12.84 and 15.73 before and after the training, respectively. The difference between the mean scores before and after the training was reported as statistically significant $(\mathrm{P}<0.01)$.

Based on the mean score of the knowledge test before the training, the students with certain introductory features, including, an age of 26 years, male gender, 0 or 1 sibling, no habit of smoking and drinking alcohol, high school graduate mother, university graduate father, and staying in the dormitory, had higher scores. According to the mean

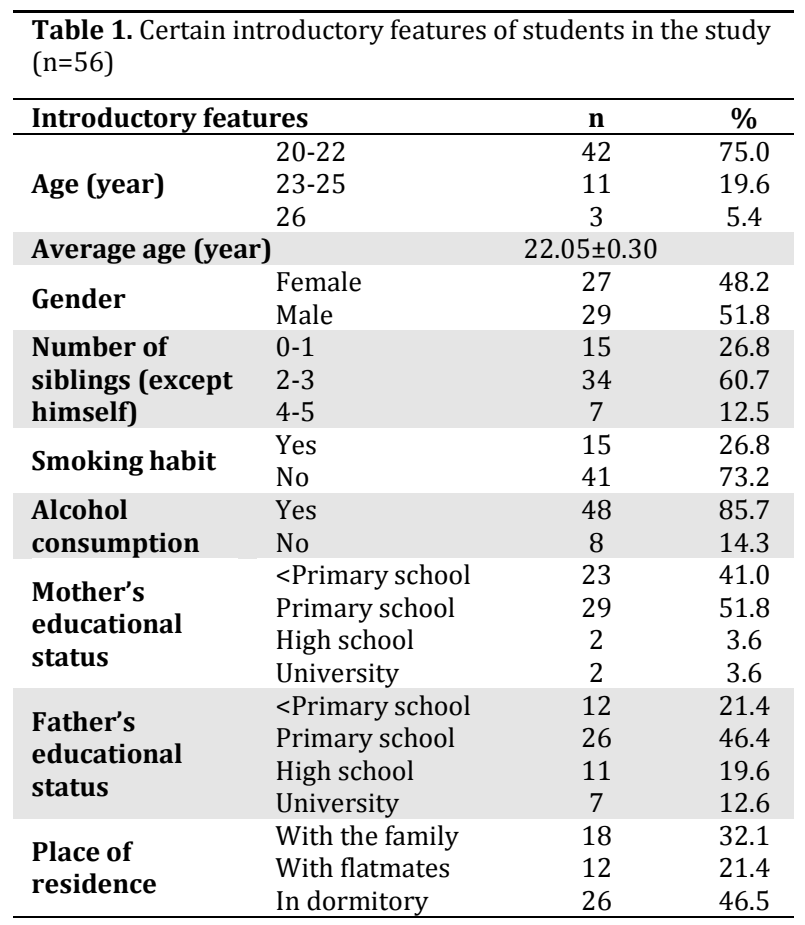




\begin{tabular}{|c|c|c|c|}
\hline \multicolumn{2}{|c|}{ Introductory features with respect to testicular cancer and TSE } & \multirow{2}{*}{$\begin{array}{c}\mathbf{n} \\
53\end{array}$} & \multirow{2}{*}{$\begin{array}{c}\% \\
94.6\end{array}$} \\
\hline & Yes & & \\
\hline Have you heard of testicular cancer? & No & 3 & 5.4 \\
\hline \multirow{2}{*}{ Have you learned about testicular cancer? } & Yes & 42 & 75.0 \\
\hline & No & 14 & 25.0 \\
\hline \multirow{5}{*}{$\begin{array}{l}\text { From which sources did you get information } \\
\text { about testicular cancer? }(n=42)\end{array}$} & TV/Radio & 5 & 11.9 \\
\hline & Internet & 13 & 30.9 \\
\hline & Books & 10 & 23.8 \\
\hline & Seminars/Meetings & 5 & 11.9 \\
\hline & Health professionals & 9 & 21.5 \\
\hline \multirow{2}{*}{ Have you heard of TSE? } & Yes & 47 & 83.9 \\
\hline & No & 9 & 16.1 \\
\hline \multirow{2}{*}{$\begin{array}{l}\text { Have you received training for testicular cancer } \\
\text { and TSE? }\end{array}$} & Yes & 23 & 41.1 \\
\hline & No & 33 & 58.9 \\
\hline \multirow{2}{*}{ Do you perform TSE?* $(n=29)$} & Yes & 6 & 19.6 \\
\hline & No & 23 & 80.4 \\
\hline \multirow{4}{*}{ Why do not you perform TSE?* $(n=23)$} & Accepting it as a sin & 6 & 25.7 \\
\hline & I do not know how to perform TSE & 10 & 43.6 \\
\hline & Because I am scared & 7 & 30.7 \\
\hline & Others & - & - \\
\hline
\end{tabular}

TSE: Testicular self-examination

* Only male students answered.

score of the knowledge test after the training, it was determined that the students within the age range of 20-22 years, with male gender, 2 or 3 siblings, no habit of smoking and drinking alcohol, university graduate mother and father, and living with the family at home had higher scores. Table 4 tabulates a comparison of the mean scores of the students with respect to testicular cancer and TSE based on the certain introductory features of the students.

The mean score of the knowledge test before the training in the students performing TSE was higher than that reported for the subjects not performing

\begin{tabular}{|c|c|c|c|c|c|c|c|c|c|}
\hline \multirow{3}{*}{ Questions concerning testicular cancer and TSE } & \multicolumn{4}{|c|}{ Before training } & \multicolumn{4}{|c|}{ After training } & \multirow{3}{*}{ P-value } \\
\hline & \multicolumn{2}{|c|}{ True } & \multicolumn{2}{|c|}{ False } & \multicolumn{2}{|c|}{ True } & \multicolumn{2}{|c|}{ False } & \\
\hline & $\mathbf{n}$ & $\%$ & $\mathbf{n}$ & $\%$ & $\mathbf{n}$ & $\%$ & $\mathbf{n}$ & $\%$ & \\
\hline \multicolumn{10}{|l|}{ In testicular cancer } \\
\hline There is no other diagnostic method other than TSE (F) & 39 & 69.6 & 17 & 30.4 & 49 & 87.5 & 7 & 12.5 & $0.024^{*}$ \\
\hline $\begin{array}{l}\text { There is a high chance of regression with early diagnosis and } \\
\text { treatment }(\mathrm{T})\end{array}$ & 44 & 78.6 & 12 & 21.4 & 52 & 92.9 & 4 & 7.1 & $0.020^{*}$ \\
\hline Cancerous masses usually settle in the epididymis $(\mathrm{T})$ & 38 & 67.9 & 18 & 32.1 & 45 & 80.4 & 11 & 19.6 & 0.163 \\
\hline $\begin{array}{l}\text { With the surgical removal of one of the testicles, sexual activity in the } \\
\text { individual disappears (F) }\end{array}$ & 40 & 71.4 & 16 & 28.6 & 45 & 80.4 & 11 & 19.6 & 0.279 \\
\hline Individuals fail in their sexual life (F) & 25 & 44.6 & 31 & 55.4 & 38 & 67.9 & 18 & 32.1 & $<0.001^{* * *}$ \\
\hline $\begin{array}{l}\text { The average passage of time between the first time the lesion in the } \\
\text { testicle is noticed by the patient and the definitive treatment is } 1 \\
\text { year (F) }\end{array}$ & 17 & 30.4 & 39 & 69.6 & 25 & 44.6 & 31 & 55.4 & 0.073 \\
\hline $\begin{array}{l}\text { Individuals who have a family history of testicular cancer are more } \\
\text { likely to have testicular cancer (T) }\end{array}$ & 47 & 83.9 & 9 & 16.1 & 52 & 92.9 & 4 & 7.1 & 0.096 \\
\hline The most important reason is the undescended testicle (T) & 34 & 60.7 & 22 & 39.3 & 49 & 87.5 & 7 & 12.5 & $0.002^{* *}$ \\
\hline It is especially common in male cases under 15 years of age $(F)$ & 41 & 73.2 & 15 & 26.8 & 40 & 71.4 & 16 & 28.6 & 0.849 \\
\hline \multicolumn{10}{|l|}{ TSE } \\
\hline Performing for early diagnostic purposes is important (T) & 52 & 92.9 & 4 & 7.1 & 55 & 98.2 & 1 & 1.8 & 0.083 \\
\hline $\begin{array}{l}\text { Should be performed in a sitting position once awakened in the } \\
\text { morning }(F)\end{array}$ & 32 & 57.1 & 24 & 42.9 & 44 & 78.6 & 12 & 21.4 & $0.017^{*}$ \\
\hline Should be performed standing against a mirror $(\mathrm{T})$ & 38 & 67.9 & 18 & 32.1 & 47 & 83.9 & 9 & 16.1 & $0.038^{*}$ \\
\hline It is more convenient to perform it after a hot bath or shower $(\mathrm{T})$ & 34 & 60.7 & 22 & 39.3 & 48 & 85.7 & 8 & 14.3 & $<0.001^{* * *}$ \\
\hline $\begin{array}{l}\text { There is no need to check for any changes or swelling in the testicle } \\
\text { skin while performing (F) }\end{array}$ & 44 & 78.6 & 12 & 21.4 & 47 & 83.9 & 9 & 16.1 & 0.444 \\
\hline Each teste should be examined with two hands (T) & 36 & 64.3 & 20 & 35.7 & 51 & 91.1 & 5 & 8.9 & $<0.001^{* * *}$ \\
\hline $\begin{array}{l}\text { It is performed by pressing the testicle between the middle finger and } \\
\text { thumb next to the testicle (F) }\end{array}$ & 9 & 16.1 & 47 & 83.9 & 16 & 28.6 & 40 & 83.9 & 0.109 \\
\hline $\begin{array}{l}\text { It should be examined whether the testicle has grown, hardened, or } \\
\text { changed according to the previous examination }(\mathrm{T})\end{array}$ & 50 & 89.3 & 6 & 10.7 & 53 & 94.6 & 3 & 5.4 & 0.322 \\
\hline It is normal for one testicle to be slightly larger than the other (T) & 27 & 48.2 & 29 & 51.8 & 34 & 60.7 & 22 & 39.3 & 0.240 \\
\hline The advantages of performing TSE includes its safety (T) & 43 & 76.8 & 13 & 23.2 & 53 & 94.6 & 3 & 5.4 & $0.011^{*}$ \\
\hline $\begin{array}{l}\text { It is enough to routinely be performed by the person himself once } \\
\text { every } 3 \text { months }(F)\end{array}$ & 25 & 44.6 & 31 & 55.4 & 34 & 60.7 & 22 & 39.3 & 0.095 \\
\hline
\end{tabular}
every 3 months (F)

TSE: Testicular self-examination; F: False; T: True

McNemar's test; ${ }^{*} \mathrm{P}<0.05$; ${ }^{* *} \mathrm{P}<0.01$; ${ }^{* * *} \mathrm{P}<0.001$ 


\begin{tabular}{|c|c|c|c|c|c|c|c|c|}
\hline \multirow{2}{*}{\multicolumn{2}{|c|}{ Introductory features }} & \multicolumn{2}{|c|}{ Before training } & \multirow{2}{*}{ P-value* } & \multicolumn{2}{|c|}{ After training } & \multirow{2}{*}{ P-value* } & \multirow{2}{*}{ P-value ** } \\
\hline & & True & False & & True & False & & \\
\hline \multirow{3}{*}{ Age (year) } & $20-22$ & 11.33 & 8.67 & & 16.00 & 4.00 & \multirow{3}{*}{0.943} & 0.166 \\
\hline & $23-25$ & 12.36 & 7.64 & 0.548 & 15.45 & 4.55 & & $<0.001$ \\
\hline & 26 & 12.98 & 7.02 & & 15.69 & 4.31 & & $<0.001$ \\
\hline \multirow{2}{*}{ Gender } & Female & 12.63 & 7.37 & & 15.58 & 4.42 & \multirow{2}{*}{0.851} & $<0.001$ \\
\hline & Male & 12.88 & 7.12 & 0.746 & 15.72 & 4.28 & & $<0.001$ \\
\hline \multirow{3}{*}{$\begin{array}{l}\text { Number of } \\
\text { siblings }\end{array}$} & $0-1$ & 13.13 & 6.87 & & 15.20 & 4.80 & \multirow{3}{*}{0.620} & $<0.001$ \\
\hline & $2-3$ & 12.94 & 7.06 & 0.262 & 15.94 & 4.06 & & $<0.001$ \\
\hline & $4-5$ & 11.14 & 8.86 & & 15.29 & 4.71 & & 0.140 \\
\hline \multirow{2}{*}{ Smoking habit } & Yes & 12.60 & 7.40 & & 14.73 & 5.27 & \multirow{2}{*}{0.112} & $<0.001$ \\
\hline & No & 12.83 & 7.17 & 0.190 & 16.00 & 4.00 & & 0.042 \\
\hline \multirow{2}{*}{$\begin{array}{l}\text { Alcohol } \\
\text { consumption }\end{array}$} & Yes & 11.71 & 8.29 & & 14.86 & 5.14 & \multirow{2}{*}{0.318} & $<0.01$ \\
\hline & No & 12.90 & 7.10 & 0.308 & 15.90 & 4.10 & & 0.177 \\
\hline \multirow{4}{*}{$\begin{array}{l}\text { Mother's } \\
\text { educational } \\
\text { status }\end{array}$} & $<$ Primary school & 12.00 & 8.00 & & 15.57 & 4.43 & \multirow{4}{*}{0.912} & $<0.001$ \\
\hline & Primary school & 13.24 & 6.76 & & 15.66 & 4.34 & & $<0.001$ \\
\hline & High school & 15.00 & 5.00 & 0.288 & 15.50 & 4.50 & & 0.500 \\
\hline & University & 12.50 & 7.50 & & 17.00 & 3.00 & & 0.500 \\
\hline \multirow{4}{*}{$\begin{array}{l}\text { Father's } \\
\text { educational } \\
\text { status }\end{array}$} & $<$ Primary school & 12.86 & 7.14 & \multirow{4}{*}{0.954} & 14.86 & 5.14 & \multirow{4}{*}{0.686} & 0.188 \\
\hline & Primary school & 12.62 & 7.38 & & 15.46 & 4.54 & & $<0.001$ \\
\hline & High school & 12.64 & 7.36 & & 16.09 & 3.91 & & 0.039 \\
\hline & University & 13.17 & 6.83 & & 16.17 & 3.83 & & 0.020 \\
\hline \multirow{3}{*}{ Place of residence } & With family at home & 12.78 & 7.22 & & 16.39 & 3.61 & \multirow{3}{*}{0.292} & $<0.001$ \\
\hline & With flatmates & 12.25 & 7.75 & 0.754 & 15.75 & 4.25 & & 0.013 \\
\hline & In dormitory & 13.00 & 7.00 & & 15.12 & 4.88 & & 0.011 \\
\hline
\end{tabular}

TSE. Furthermore, the mean score of the knowledge test after the training among the students performing TSE was observed to be higher. The in-group difference between the mean scores of the knowledge test before and after the training in the students performing TSE was observed to be 0.032. However, the rate of the students performing TSE was reported as $19.6 \%$ before the training that increased to $100 \%$ after the training.

\section{Discussion}

In this study evaluating the training program given to nursing students on testicular cancer and TSE, the average age of the students participating in the study was $22.05 \pm 0.30$ years. It was observed that the rate of the students not smoking but drinking alcohol was high, and the educational status of the parents of the majority of the students was poor (primary school graduates). In a study carried out by Pour and Çam, the average age of the students participating in the study was $21.78 \pm 1.65$ years, and it was determined that smoking and alcohol consumption was as high as $50 \%$. Regarding the educational levels of the parents, it was observed that the ratio of parents with primary school level of education was higher (20). When studies evaluating the level of knowledge of individuals on testicular cancer and TSE were examined, it was observed that there were introductory features similar to those reported for the present study $(17,21)$.

In the current study, the vast majority of students stated that they heard about testicular cancer and TSE (94.6\% and $83.9 \%$, respectively). In another study conducted by Rudberg et al. on university students in Sweden, it was reported that the rates of knowledge of testicular cancer and TSE were $11.3 \%$ and $5.6 \%$ respectively. Pour and Çam, in their studies performed on 65 male students, reported that the rates of knowledge of testicular cancer and TSE were $80.4 \%$ and $72.4 \%$, respectively. In a study carried out by Kennett et al. in the UK, the rates of knowledge of testicular cancer and TSE were reported as $75.8 \%$ and $79.9 \%$, respectively $(20-22)$. The fact that the rates of hearing about testicular cancer and TSE in the present study are higher than those reported in previous studies suggests that this finding was due to the selection of the participants from a health department.

In this study, it was concluded that two-thirds of the students received information about testicular cancer; however, more than half of them did not receive any training for testicular cancer and TSE. It has been determined that the internet was the main source of information. In a study conducted by Atuhaire et al., the participants stated that the sources they learned about TSE were health workers/hospitals by $15.8 \%$ and friends/peers by $12.1 \%$ (23). In another study performed by Rudberg et al. on 727 students in Sweden, $11.3 \%$ and $5.6 \%$ of the population were determined to receive previous education about testicular cancer and TSE, respectively. In addition, the main source of information was reported to be the media (21).

Both in the current study and the literature regarding testicular cancer, which is the most common malignant tumor among males within the age range of 15-35 years, it was suggested that individuals did not receive sufficient and necessary information for early diagnosis, indicating that the 
aim of early diagnosis cannot be adequately achieved. High social media or internet ratio as a source of information makes it much more important to include educational information on testicular cancer and TSE in the media or public service ads to enable individuals to have access to reliable information.

In the present study, the majority of the male students reported that the primary reason why they did not perform TSE among other reasons was that they did not know how to do it. In a study conducted by Peltzer and Pengpid on 2,061 male undergraduate university students from five universities in five countries in Asia and Europe, $82.4 \%$ of the students did not know how to perform TSE. It was also observed that approximately $80 \%$ of the subjects in Bangladesh and Singapore and $87.8 \%$ of the participants in Madagascar did not know how to perform TSE (24).

In a study carried out by Kennett et al., approximately $60 \%$ of the study subjects reported that they did not perform TSE, and as a reason they stated that they did not know what symptoms they should check for in the testes (22). In another study conducted by Atuhaire et al., the rate of participants not performing TSE was reported as $76.4 \%$ and the reason was stated as a lack of information on TSE (23). Both in the literature $(6,16,21-24)$ and the present study, the reason that students do not know how to perform TSE is the most thought-provoking result for TSE; nevertheless, TSE application could easily be taught with simple education.

In this study, the participants were trained for testicular cancer and TSE, and it was observed that there was a statistically significant increase in their level of knowledge of the subject-matter after the training $(\mathrm{P}<0.01)$. In the aforementioned studies similar to the current study but evaluating the frequency of performing TSE instead of the level of knowledge, the results are observed to be similar to those of the present study. In a study performed by McCullagh et al. in England, a training program was maintained through a conference, increasing the frequency of performing TSE from $58.4 \%$ to $68.3 \%$. Furthermore, in a study carried out by Steadman et al. in England, practical training was used as a method, increasing the frequency of performing TSE from $40.0 \%$ to $65.0 \%(17,18)$. In the present study, the correct response rates and mean scores of the knowledge test before the training increased after the training, and the increase was significant in the group comparison $(\mathrm{P}=0.032)$, revealing the effectiveness of the training in testicular cancer and TSE.

\section{Conclusion}

In conclusion, a significant increase in the average scores of the knowledge test before the training for testicular cancer and TSE among the students can easily be achieved even with a standard awareness- raising campaign. Therefore, it is safe to state that well-planned educational activities can be beneficial for raising the awareness of society in this regard.

\section{Acknowledgments}

The authors would like to express their gratitude to the students for participating in this study.

\section{Footnotes}

Conflict of Interests: The author(s) declare no potential conflict of interest with respect to the research, authorship, and/or publication of this article.

Funding/Support: The author(s) received no funding for data collection, design of the study, data analysis, and manuscript writing

\section{References}

1. Ghoreifi A, Djaladat H. Management of primary testicular tumor. Urol Clin North Am. 2019;46(3):333-9. doi: 10.1016/ j.ucl.2019.04.006. [PubMed: 31277728].

2. Hachfeld L, MacWilliams B, Schmidt B. Physical awareness a key to improving adolescent male health: A grounded theory study of the perception of testicular self-examination in male student athletes. J Nurse Pract. 2016;12(4):243-9. doi: 10.1016/j.nurpra.2015.10.024.

3. Peltzer K, Pengpid S. Knowledge, attitudes and practice of testicular self-examination among male university students from Bangladesh, Madagascar, Singapore, South Africa and Turkey. Asian Pac J Cancer Prev. 2015;16(11):4741-3. doi: 10.7314/apjcp.2015.16.11.4741. [PubMed: 26107234].

4. Surveillance, epidemiology, and end results program. Cancer stat facts: testicular cancer. National Cancer Institute. Available at: URL: https://seer.cancer.gov/statfacts/html/testis.html; 2019.

5. World Health Organization. Cancer Statistical of Turkey. Geneva: World Health Organization; 2018.

6. Muliira JK, Nalwanga PB, Muliira RS, Nankinga Z. Knowledge, perceived risk and barriers to testicular self-examination among male university students in Uganda. J Mens Health. 2012;9(1):36-44. doi: 10.1016/j.jomh.2011.11.004.

7. Tanagho EA, McAninch JW. Testicular tumors. In: Tanagho EA, McAninch JW, editors. İstanbul: Nobel Tip Kitapevleri; 2004. P. 375-87.

8. Saab MM, Davoren M, Murphy A, Murphy D, Cooke E, Landers M. et al. Promoting men's awareness, self-examination, and help-seeking for testicular disorders: a systematic review of interventions. HRB Open Res. 2018;1:16. doi: 10.12688/ hrbopenres.12837.2. [PubMed: 32002508].

9. Thornton CP. Best practice in teaching male adolescents and young men to perform testicular self-examinations: a review. $J$ Pediatr Health Care. 2016;30(6):518-27. doi: 10.1016/ j.pedhc.2015.11.009. [PubMed: 26778347].

10. Rovito MJ, Cavayero C, Leone JE, Harlin S. Interventions promoting testicular self-examination (TSE) performance: a systematic review. Am J Mens Health. 2015;9(6):506-18. doi: 10.1177/1557988314555360. [PubMed: 25359870].

11. Albers P, Albrecht W, Algaba F, Bokemeyer C, Cohn-Cedermark G, Fizazi K, et al. EAU guidelines on testicular cancer: 2011 update. Eur Urol. 2011;60(2):304-19. doi: 10.1016/j.eururo. 2011.05.038. [PubMed: 21632173].

12. Ramim T, Mousavi SQ, Rosatmnia L, Bazyar A, Ghanbari V. Student knowledge of testicular cancer and self-examination in a medical sciences University in Iran. Basic Clin Cancer Res. 2014;6(3):7-11.

13. Braga IC, Cabral J, Louro N, de Carvalho JL. Testicular cancer 
awareness and knowledge: Is it the same? Exploratory study in a mixed-gender population. J Cancer Educ. 2017;32(1):105-11. doi: 10.1007/s13187-015-0903-3. [PubMed: 26358248].

14. Kuzgunbay B, Yaycioglu O, Soyupak B, Kayis AA, Ayan S, Yavascaoglu I, et al. Public awareness of testicular cancer and self-examination in Turkey: a multicenter study of Turkish Urooncology Society. Urol Oncol. 2013;31(3):386-91. doi: 10.1016/j.urolonc.2011.01.020. [PubMed: 21429771].

15. Saab MM, Landers M, Hegarty J. Exploring men's preferred strategies for learning about testicular disorders inclusive of testicular cancer: a qualitative descriptive study. Eur J Oncol Nurs. 2017;26:27-35. doi: 10.1016/j.ejon.2016.11.001. [PubMed: 28069149].

16. Pour HA, Kunter D, Norouzzadeh R, Heidari MR. The effect of testicular self-examination education on knowledge, performance, and health beliefs of Turkish men. J Cancer Educ. 2018;33(2):398-403. doi: 10.1007/s13187-016-1132-0. [PubMed: 27815814].

17. McCullagh J, Lewis G, Warlow C. Promoting awareness and practice of testicular self-examination. Nurs Stand. 2005; 19(51):41-9. doi: 10.7748/ns2005.08.19.51.41.c3944. [PubMed: 16161515].

18. Steadman L, Quine L. Encouraging young males to perform testicular self-examination: a simple, but effective, implementtation intentions intervention. Br J Health Psychol. 2004;9 (Pt 4):479-87. doi: 10.1348/1359107042304551. [PubMed:
15509356].

19. Saab MM, Landers M, Hegarty J. Testicular cancer awareness and screening practices: a systematic review. Oncol Nurs Forum. 2016;43(1):8-23. doi: 10.1188/16.0NF.E8-E23. [PubMed: 26679456].

20. Pour AH, Çam R. Evaluation of men's knowledge, attitude and behavior about testicular self-examination and testicular cancer. Florence Nightingale J Nurs. 2014;22(1):33-8.

21. Rudberg L, Nilsson S, Wikblad K, Carlsson M. Testicular cancer and testicular self- examination: knowledge and attitudes of adolescent Swedish men. Cancer Nurs. 2005;28(4):256-62. doi: 10.1097/00002820-200507000-00003. [PubMed: 16046886].

22. Kennett A, Shaw JW, Woolley PD. Testicular self-examination amongst genitourinary medicine clinic attendees. Int J STD AIDS. 2014;25(12):844-50. doi: 10.1177/0956462414522774. [PubMed: 24516080].

23. Atuhaire C, Byamukama A, Cumber RY, Cumber SN. Knowledge and practice of testicular self-examination among secondary students at Ntare School in Mbarara District, South western Uganda. Pan Afr Med J. 2019;33:85. doi: 10.11604/pamj. 2019.33.85.15150. [PubMed: 31489063].

24. Peltzer K, Pengpid S. Knowledge, attitudes and practice of testicular self-examination among male university students from Bangladesh, Madagascar, Singapore, South Africa and Turkey. Asian Pac J Cancer Prev. 2015;16(11):4741-3. doi: 10.7314/APJCP.2015.16.11.4741. [PubMed: 26107234]. 